\title{
Optimization of Bioenergy Crop Selection and Placement Based on a Stream Health Indicator Using an Evolutionary Algorithm
}

\author{
Matthew R. Herman ${ }^{a}$, A. Pouyan Nejadhashemi a, ${ }^{\text {a, }}$, Fariborz Daneshvar ${ }^{a}$, Mohammad Abouali ${ }^{\text {a }}$, \\ Dennis M. Ross ${ }^{b}$, Sean A. Woznicki ${ }^{a}$, Zhen Zhang ${ }^{c}$ \\ ${ }^{a}$ Department of Biosystems and Agricultural Engineering, 524 S. Shaw Lane, Room 216, Michigan State University, East \\ Lansing, MI 48824, USA \\ b Department of Computer Science and Engineering, Michigan State University, East Lansing, MI 48824, USA \\ ${ }^{c}$ Physical Sciences Division, Department of Statistics, University of Chicago, Chicago, IL 60637, USA \\ * Author who correspondence should be addressed. Tel.: (517) 432-7653. Email address: pouyan@msu.edu (A. Pouyan \\ Nejadhashemi)
}

\section{Abstract}

The emission of greenhouse gases continues to amplify the impacts of global climate change. This has led to the increased focus on using renewable energy sources, such as biofuels, due to their lower impact on the environment. However, the production of biofuels can still have negative impacts on water resources. This study introduces a new strategy to optimize bioenergy landscapes while improving stream health for the region. To accomplish this, several hydrological models including the Soil and Water Assessment Tool, Hydrologic Integrity Tool, and Adaptive Neruro Fuzzy Inference System, were linked to develop stream health predictor models. These models are capable of estimating stream health scores based on the Index of Biological Integrity. The coupling of the aforementioned models was used to guide a genetic algorithm to design watershed-scale bioenergy landscapes. Thirteen bioenergy managements were considered based on the high probability of adaptation by farmers in the study area. Results from two thousand runs identified an optimum bioenergy crops placement that maximized the stream health for the Flint River Watershed in Michigan. The final overall stream health score 
was 50.93, which was improved from the current stream health score of 48.19. This was shown to be a significant improvement at the $1 \%$ significant level. For this final bioenergy landscape the most often used management was miscanthus (27.07\%), followed by corn-soybean-rye (19.00\%), corn stover-soybean (18.09\%), and corn-soybean $(16.43 \%)$. The technique introduced in this study can be successfully modified for use in different regions and can be used by stakeholders and decision makers to develop bioenergy landscapes that maximize stream health in the area of interest.

Keywords: Genetic Algorithm; Index of Biological Integrity; Stream Health; Bioenergy 


\section{Introduction}

With the recent concern for the impacts of increased greenhouse gas emissions on climate change, renewable energy sources have gained popularity due to the fact that they have a much lower environmental impact than fossil fuels. Among the renewable energy sources, perhaps biofuel has been promoted most significantly in the recent decade. This is due to the many benefits that biofuels represent, such as reduced $\mathrm{CO}_{2}$ emissions and supporting local agriculture (Farrell et al., 2006; Goldemberg 2007; Groom et al., 2008; Ragauskas et al., 2006). However, there are many negative impacts associated with biofuel production. Altering forest and grassland landuse to allow for the production of bioenergy crops has been shown to increase $\mathrm{CO}_{2}$ emissions (Searchinger et al., 2008). Furthermore the growth of bioenergy crops has led to the increase of nutrient and chemical loading in nearby water systems, which can impact the health of both the ecosystems and humans (Landis et al., 2008; Love et al., 2011; Nyakatawa et al., 2006). Therefore, decision makers need to take into account both the positive and negative impacts of biofuel production when deciding how to best apply bioenergy crops to a region.

Many studies have been conducted to evaluate the impacts of expanding bioenergy crop production on water quality and quantity. First generation bioenergy crops, such as corn, were the first plants used for biofuel production due to their easily processed starches (Goldemberg 2007). However, studies have indicated that relying on starch crops increases the chemical, nutrient, and sediment loads to nearby water systems (Egbendewe-Mondzozo et al., 2013; Love et al., 2011; Thomas et al., 2014; Wu and Liu, 2012). Furthermore, first generation bioenergy crops require more water, which increases the amount of water needed for irrigation (Gasparatos et al., 2013; Wu and Liu, 2012). In order to mitigate these disadvantages, second generation bioenergy crops were introduced. These included lignocellulosic crops such as popular and 
miscanthus (Wu and Liu, 2012). Compared to the implementation of first generation bioenergy crops, the use of second generation bioenergy crops these crops reduces both the pollutant loadings in nearby water systems and the water yield (Love et al., 2011; Thomas et al., 2014; Wu and Liu, 2012). However, applying second generation bioenergy crops to natural environments, such as forests or grassland, could lead to increased pollutants loads and greater water demands (Wu and Liu, 2012).

To monitor the environmental impacts of anthropogenic activities, stream health is often used (Karr and Dudley, 1981; Pander and Geist, 2013; Walters et al., 2009). Stream health can be defined as the chemical, physical, and biological condition of a stream (Karr, 1999; Maddock, 1999). Biological indictors are often used when determining stream health due to their ability to not only represent not only the biotic characteristics of stream but also the physical and chemical (abiotic) characteristics (Brazner et al., 2007; Leigh et al., 2013; Pelletier et al., 2012).

Furthermore, stream health can be modeled and calculated for all stream segments within a watershed (Einheuser et al., 2012). This allows environmental resource managers to use stream health scores to identify degraded regions and allocate resources to restore the ecosystems with the greatest needs (Butcher et al., 2003; Pelletier et al., 2012; Walters et al., 2009).

To minimize the environmental impacts of large scale bioenergy crop expansion, it is important to optimize the design of the bioenergy crop landscape for the study area. One approach is to examine a landscape design and monitor it for several years to determine which design is the best for the region. However, this approach is impractical due to cost and time constraints. Therefore, modeling approaches are typically preferred, which are inexpensive and faster alternatives to monitoring (Arabi et al., 2006; Einheuser et al., 2013a; Giri et al., 2012). 
However, modeling still has its own limitations. Access to detailed datasets and computational power are required when using models (Einheuser et al., 2013a).

As presented above, with respect to evaluating bioenergy crop expansion, numerous studies have been done but to the best of our knowledge, this is the first study that combines the concept of stream health for optimizing the placements of different bioenergy crops. This will be completed through the main objectives, which are: (1) predict stream health conditions beyond the monitoring points of a biological indicator, and (2) develop a series of bioenergy crop management scenarios that maximize stream health within a watershed.

\section{Materials and methods}

\subsection{Study area}

The region used for this study was the Flint River Watershed in Michigan (Figure 1). This is an 8-digit hydrologic unit code (HUC 04080204) and is part of the Saginaw River Watershed, which has been identified as an area of concern due to bacteria, excessive nutrients, habitat loss, and hazardous chemicals, which has led to the degradation of the environmental conditions in the region (MSU Planning \& Zoning Center, 2012). The Flint River Watershed discharges into the Shiawassee River, with the final outlet for the region discharging into Lake Huron at the mouth of the Saginaw River. The region has a total area of $3445 \mathrm{~km}^{2}$, and is dominated by forest (40\%), followed by agricultural land (25\%), pasture (18\%), urban (16\%), and finally wetland and water (both 1\%). While the largest individual landuse type is forest (40\%), anthropogenic activities (agriculture, pasture, and urban) impact over half the region $(59 \%)$.

Figure 1. 


\subsection{Data collection}

\subsubsection{Physiographic data}

To develop the stream health models for the Flint River Watershed, several spatial and temporal datasets were obtained. These datasets included topography, land use, soil characteristics, climate data, and management practices. Thirty-meter spatial resolution National Elevation Data was used to represent the topography of the region and was obtained from the US Geological Survey (USGS) (NED, 2014). Thirty-meter spatial resolution 2012 Cropland Data Layer (CDL) was used to represent the landuse in the study area and was obtained from the United States Department of Agriculture-National Agricultural Statistics Service (USDA_NASS) (NASS, 2012). Soil characteristics data was obtained from the Natural Resources Conservation Service (NRCS) Soil Survey Geographic (SSURGO) database at a scale of 1:250,000 (NRCS, 2014). Precipitation and temperature data were obtained from the National Climatic Data Center (NCDC). Within the Flint River Watershed, six precipitation and six temperature stations were used to supply daily climatological information from 1998 to 2005 . Other climate data such as relative humidity, solar radiation, and wind speed were obtained from the SWAT weather generator (Neitsch et al., 2011). The stream network and subbasins were created from a 1:24,000 National Hydrography Dataset plus (NHDPlus) and refined by the Michigan Institute for Fisheries Research for stream health studies. Each of the 3807 subbasins from this dataset contains an individual stream and is considered to be physicochemically, geomorphologically, and biologically unique (Einheuser et al., 2013a). Bioenergy management operations, schedules, and crop rotations were obtained from the Michigan State University Extension, as presented by Love and Nejadhashemi (2011) for the study area. 


\subsubsection{Biological data}

Fish are a commonly used biological indicator of stream health. This is due to their wide distribution and sensitivity to a variety of stressors (Karr, 1981; Mack, 2007; Zhu and Chang, 2008; Navarro-Llácer et al., 2010; Krause et al., 2013; Herman and Nejadhashemi, 2015). Furthermore, due to their life cycles and seasonal migrations they are used to provide regional scale views of stream conditions (Karr, 1981). For this study, the Index of Biotic Integrity (IBI) was used to evaluate stream health conditions. First introduced by Karr (1981), the IBI is a multimetric index that evaluates stream health by utilizing twelve metrics that can be broadly grouped into three categories: species diversity, trophic composition, and abundance of fish communities. However, to better represent the regional fish communities, a modified IBI was introduced by Lyons (1992) in which the metrics and scoring system were updated. The ten metrics in the new system were given a score of 0 to 10 , with 10 representing non-disturbed conditions within a stream (Lyons, 1992). These were summed just to calculate the overall IBI score. However, the final score should be adjusted under a certain ecological conditions (number of individuals per $300 \mathrm{~m}^{2}$ is less than 50 or percent of deformities, eroded fins, lesions, or tumors in fish is greater or equal to $4 \%$ ) using the correction factors, which can reduce the overall IBI score up to 20 (Lyons, 1992). After rounding any negative IBI scores to 0, the final stream health IBI scores ranged from 0 to 100 and can be used to compare the conditions in different streams.

This range of scores was divided into five stream health classes (very poor, poor, fair, good, and excellent) based on Lyons' warmwater classifications (1992), the ranges for each steam health class are as follows: stream health scores ranging from 0 to 19 were considered to have very poor stream health; 20 to 29 were considered to have poor stream health; 30 to 49 were considered to 
have fair stream health; 50 to 64 were considered to have good stream health; and 65 to 100 were considered to have excellent stream health.

Observed IBI scores were obtained from 57 sampling sites (Figure 1) from the Michigan Department of Natural Resources Fish Collection System and the Michigan River Inventory dataset (Seelbach et al., 1997). One a year sampling was performed during the months of June through September for 16 consecutive years (1982 to 2007) ( Seelbach et al., 1997; Einheuser et al., 2013b). The final IBI score was calculated based on the average score calculated during the sampling period. Both wadeable and non-wadeable sites (80-960 $\mathrm{m}$ stretches and 1,610 m stretches, respectively) were sampled through the use of several single-pass electrofishing methods including backpack, tow-barge, and boom units depending on stream size (Einheuser et al., 2013b).

\subsection{Modeling process}

In order to accomplish the goals of this study, that expansion of bioenergy crop productions while minimizing the environmental impacts of this landuse change, two modeling phases were established, the development phase and the scenario phase (Figure 2). The purpose of the development phase was to develop a stream health model capable of estimating stream health scores (IBI) beyond the monitoring points. To achieve this a biophysical Soil and Water Assessment Tool (SWAT) model was calibrated and validated to simulate the daily stream flows from 1998 to 2005 for all stream segments within the Flint River Watershed. These simulated flows were used to calculate 171 hydrological indices using the Hydrological Index Tool (HIT). Given the large number of variables (171), Bayesian variable selection was used to identify the key indices that would be used for developing the stream health score model using an Adaptive Neruro Fuzzy Inference System (ANFIS) technique. After developing the stream health models, 
they were used in the scenario phase, where thirteen different bioenergy management practices were applied to agricultural, pasture, and marginal lands within the watershed. The scenario phase utilizes the evolutionary algorithm technique known as Genetic Algorithms (GA) to find a near optimum solution by maximizing the stream heath index (MathWorks. 2015). For each iteration, SWAT was used to simulate daily stream flows for each scenario, HIT was used to calculate the hydrological indices selected in the development phase, and ANFIS was used to estimate the IBI scores for each stream segment, and the weighted average of all the individual IBI scores was calculated for each bioenergy scenario, which was considered as criteria for crop placement. This process was repeated until a near optimum solution was achieved.

\section{Figure 2.}

\subsubsection{Development phase}

\subsubsection{Soil Water Assessment Tool}

Daily stream flow data was modeled for all stream segments in the Flint River Watershed using the physically based Soil Water Assessment Tool. SWAT was developed by the USDA Agricultural Research Service (USDA-ARS) and Texas A\&M AgriLife Research (Texas A\&M University System, 2013). It is used to model streamflow, sediment, nutrient, and pesticide loadings using physiographical and climatological data including land use, river networks, topography, soils, agricultural rotations, management operations, and climatological information (Gassman et al., 2007; Neitsch et al., 2011).

For the Flint River Watershed, the SWAT model was calibrated and validated against observed daily stream flow data from the USGS gauging station on the Flint River near Flint, MI (041485100) from 1996 to 2005. The first two years (warm-up period) were used to stabilize the model. Calibration was preformed from 1998 to 2001 while validation was preformed from 2002 
to 2005. Calibration and validation were considered successful when the following criteria were met (Moriasi et al., 2007): a) Nash-Sutcliffe model efficiency coefficient (NSE) $\geq 0.5$, b) rootmean-squared error-observations standard deviation ratio $(\mathrm{RSR}) \leq 0.7$, c) and percent bias $($ PBIAS $)< \pm 25$.

\subsubsection{Hydrological Index Tool}

For each of the 3807 stream segments in the Flint River Watershed, 171 biologically relevant stream flow indices were calculated using the Hydrological Index Toot (HIT). HIT was developed by the USGS as part of the Hydroecological Integrity Assessment Process (HIP) (EPA, 2014). The indices calculated by HIT were first introduced by Olden and Poff (2003) and can be divided in to five main categories: magnitude, frequency, duration, timing, and rate of change. Magnitude indices describe the availability of water in the stream segment and are used to identify the habitat suitability (Richter et al., 1996). Frequency indices describe how often hydrological events, such as droughts or floods, have profound impacts on organism populations (Kennard et al., 2010). Duration indices are used to describe the relationship between the lengths of hydrological events and the impacts on aquatic organism growth stages (Kennard et al., 2010). Timing indices are describe the occurrence of hydrological events throughout the year. This index is usually used to monitor organism growth (Stewart et al., 2005). Rate of change indices describe the speed at which conditions within the streams change, which can be used to identify organism access to adequate water or the impacts of extreme hydrological events on organism populations (Richter et al., 1996).

In order to make the stream health model better represent the ecological conditions of stream networks, two sets of models were developed according to the river continuum concept (Vannote et al., 1980). The river continuum concept describes the changes in biotic and abiotic 
stream characteristics that are expected in different regions of river systems (EPA, 2014). The ecological regions of a river system according to this concept are: headwaters (stream orders 13), medium-sized streams (stream orders 4-6), and large rivers (stream orders > 6) (Vannote et al., 1980). For this study stream were divided into two classes (stream orders $1-3$ and > 3).

\subsubsection{Variable selection}

Bayesian variable selection ranks the most appropriate variables for the stream health models (Woznicki et al., 2015). In addition, this technique helps with reducing the number of variables in the model. Using Bayesian variable selection, the top five variables for each stream class (orders $1-3$, and $>3$ ) were identified and used to develop the final stream health models using ANFIS.

Bayesian variable selection utilizes reversible jump Markov Chain Monte Carlo (MCMC) methods to potentially explore all possible combinations of variables to find the model that best fits the observed data (Green, 1995; Lunn et al., 2006). This is done by selecting different variable sets (MCMC) and randomly adding or removing variables, and comparing each set's model likelihood before and after each variable addition/subtraction. The model with a comparably high likelihood is likely to be kept and then has a variable added or removed again. This process is repeated until multiple MCMC runs with distinct initial models converge by monitoring the model parameters and likelihoods, which signifies that the most probable models have been identified. For this study, five MCMC chains were used to insure the most probable combinations of variables were selected, each chain had a unique set of initial variables..

\subsubsection{Stream health model}

The final step in the model development phase is the development of the stream health predictor models that are capable of estimating IBI scores for each stream segment in the Flint 
River Watershed. This was accomplished through the use of a technique known as adaptive neuro-fuzzy inference system (ANFIS). ANFIS is a multi-layer network that utilizes artificial neural networks and fuzzy logic to create membership functions (MFs) while minimizing the output errors (Jang, 1993). MFs describe the degree of association for each variable in the stream health models and ranges from full exclusion (0) to full inclusion (1) (Hamaamin, 2014). For this study ANFIS was used due to the fact that it is well-suited to capture the uncertainty and complexity of environmental systems (Adriaenssens et al., 2004; Chen and Mynett, 2003; Metternicht, 2001; Woznicki et al., 2015).

The variables selected by the Bayesian technique were used to develop the ANFIS model. This was performed using the Fuzzy Logic Toolbox in MATLAB R2013b (MathWorks, 2014). The Fuzzy Logic Toolbox utilizes five different MF shapes: triangular, trapezoidal, generalized bell, Gaussian, and Gaussian composite. For each set of five variables all possible combinations of variables and MFs were evaluated to select the best variable and MF set. The criteria for selecting the best variable and MF set is the highest coefficient of determination $\left(R^{2}\right)$ and the lowest root-mean-square error (RMSE) values. After selecting the best variable and MF set, 10fold cross-validation was preformed to train, test, and identify the best ANFIS model. The 10fold cross-validation technique divided the observed data into ten equal groups and then trains the models on $90 \%$ of the data ( 9 folds) and then tests it on the last $10 \%$ of the data ( 1 fold). This process is repeated 10 times for each model using all ten set of testing data (Hamaamin et al., 2013). 


\subsubsection{Scenario phase}

\subsubsection{Bioenergy managements}

Based on the work of Love and Nejadhashemi (2011), thirteen different bioenergy managements were considered when determining which management or combination of managements had the largest probability to be implemented in the study area. The managements include: continuous canola, continuous corn, continuous corn stover (40 percent residue removal), continuous rye, continuous sorghum, continuous soybean, corn-soybean, cornsoybean-rye, corn stover (40 percent residue removal)-soybean, miscanthus, native grass, and switchgrass. These were selected due to their production capability, the ease for farmers to obtain the planting and harvesting equipment, and the capital investment needed to plant, grow, and harvest each bioenergy crop (Love and Nejadhashemi, 2011). Detailed bioenergy rotations are provided in Table 1.

Table 1.

Hydrological variables generated under the base condition and the thirteen crop rotation scenarios were compared to determine whether introducing bioenergy crop scenarios had a significant impact on the hydrological variables used in the stream health models. Furthermore, the hydrological variables were compared among the bioenergy scenarios to determine if the hydrology of the system was significantly affected. To do this, a pairwise comparison of the hydrological means was performed using the Tukey test (Ott and Longnecker, 2001). The Tukey test is commonly used multiple comparison statistical test that is performed to identify means that are significantly different from each other (Nejadhashemi et al., 2009). This test was preformed using MATLAB R2013b. 


\subsubsection{Optimizing bioenergy management placement}

The very first step in any optimization process is defining an objective function. In this project, the objective function is to assign the bioenergy management options among the possible land parcels in such a way that the overall stream health (OSH) score, a number between 0 and 100, is maximized. This can be written as a minimization problem as follows:

$$
\min _{P_{i}} f_{o b j}\left(P_{1}, P_{2}, \cdots, P_{n}\right),
$$

where,

$$
f_{\text {Obj }}\left(P_{1}, P_{2}, \cdots, P_{n}\right)=100-\operatorname{OSH}\left(P_{1}, P_{2}, \cdots, P_{n}\right),
$$

and OSH is defined as:

$$
\operatorname{OSH}\left(P_{1}, P_{2}, \cdots, P_{n}\right)=\frac{\sum_{i=1}^{m} L_{i} \cdot I B I_{i}}{\sum_{i=1}^{m} L_{i}} .
$$

In above equations, $m$ is the total number of available land parcels or Hydrological Response Units (HRUs), $n$ is the total number of target HRUs that a certain bioenergy management $\left(P_{i}\right)$ is going to be implemented, and $L_{i}$ is the stream length. In this project $m=3807, n=1303$, and there are 13 different bioenergy crop managements each given an integer number from 1 to 13 ; thus:

$$
\forall i, i \in I_{1303}: \quad P_{i} \in I_{13} \text {, }
$$

where,

$$
I_{n}:=\{1,2, \cdots, n\}
$$


This means for our objective function, i.e. $f_{o b j}: I^{1303} \rightarrow R$, there are $13^{1303} \approx O(1452)$ unique management scenarios. Obviously, it is impossible to test all the combinations and choose the best. Moreover, considering that calculating OSH score requires running SWAT, which for this project it takes between $10 \mathrm{~min}$ and $15 \mathrm{~min}$ to execute on a desktop computer equipped with an Intel® i7-4770 CPU running at 3.4GHz and 16GB of Random Access Memory (RAM), the total number of scenarios that can be actually tested is very limited.

A parallel implementation of Genetic Algorithm (GA), available in MATLAB 2013b®, was used to search for the global minimum of the objective function, i.e. searching for a bioenergy management scenario that minimizes the objective function by maximizing the OSH score. The objective function was also written in MATLAB®, which described below:

- The function is called with a vector containing 1303 elements, all integers between 1 and 13.

- Depending on the number of parallel MATLAB workers, multiple concurrent SWAT runs are possible. To prevent SWAT from overwriting the output files, each instance of SWAT needs to be executed in a separate folder. Hence, each MATLAB's parallel worker need to setup a unique working directory or folder. This unique working folder is named PID_XXXX where $X X X X$ is the Process ID (PID) of the worker; hence, guaranteeing the uniqueness of the folder name. Each worker copies the base management scenario along with all other files required to run SWAT into their corresponding working folder. This step is only performed once per parallel worker.

- The function checks if the input scenario is already evaluated before by checking it against past scenarios database. If the current scenario is found in the database, the score is returned from the database and the function execution is completed. It was noted that 
GA implementation of MATLAB does not keep track of the candidates that are already evaluated and it might reevaluate the same scenario over and over again. Considering the time that is required to run SWAT and aggregate its output into a single score, this approach will enhance the performance and avoids unnecessary redundant SWAT runs.

- The required management files based on the input scenarios are copied to the working folder to be processed by SWAT.

- The MATLAB's parallel worker launches an instance of SWAT in its working directory and the watershed is analyzed.

- Once the SWAT run is completed, MATLAB reads the SWAT output files and calculates the OSH score.

- The current scenario along with its OSH score is appended to the past scenarios database.

Default MATLAB's options for GA were used, except that the initial population was set to 48 and the initial seed was randomly generated. This approach avoids converging to local minima.

\section{Results and discussion}

\subsection{SWAT model calibration/validation}

NSE values are above 0.5 with 0.582 for calibration and 0.566 for validation, RSR values are under 0.7 with 0.647 for calibration and 0.659 for validation, and PBIAS values are within a range of \pm 25 with 13.33 for calibration and 17.89 for validation. This shows that the SWAT model was successfully calibrated and validated and could be used to simulate daily stream flow data for all stream segments in the study. In addition to statistical evaluation of the model performance, Figure A1 was provided to visualize simulated and observed flows. The blue line 
represents the observed data and the red dashed line is the simulated daily stream flows that present a very good match.

\subsection{Stream health model}

ANFIS was used to develop the final stream health models and used the top five variables selected from the Bayesian variable selection as inputs. Stream health models were developed by evaluating all combinations of variables and type (triangular, trapezoidal, generalized bell, Gaussian, and Gaussian composite) and number (two, three, and four) of MFs. Both linear and constant ANFIS models were included in this analysis. Tables A1 and A2 (Supplementary Materials) show a complete list of the ANFIS models evaluated for stream orders 1 to 3 and stream orders $>3$, respectively.

Magnitude indices describe the availability of water in the stream segment and are used to identify the habitat suitability (Richter et al., 1996). Frequency indices describe how often hydrological events, such as droughts or floods, have profound impacts on organism populations (Kennard et al., 2010). Duration indices are used to describe the relationship between the lengths of hydrological events and the impacts on aquatic organism growth stages (Kennard et al., 2010). Timing indices are describe the occurrence of hydrological events throughout the year. This index is usually used to monitor organism growth (Stewart et al., 2005). Rate of change indices describe the speed at which conditions within the streams change, which can be used to identify organism access to adequate water or the impacts of extreme hydrological events on organism populations (Richter et al., 1996).

The best stream health models were selected based on the highest $R^{2}$ and lowest RMSE values. The final stream model for stream orders 1 to 3 is a constant model that was best 
described by two duration variables, which describe the length of hydrological events and impact organism growth stages. Considering the lower flows in stream orders 1 to 3 it makes sense that the length of different types of flows would have a larger impact on the biological community. The variables selected for the final model for stream orders 1 to 3 were: the low flow pulse duration (DL16) and the annual minimum daily flow divided by the median for the entire record (DL11). The first variable (DL16) had two generalized bell MFs while the second variable (DL11) had three generalized bell MFs. The RMSE and $R^{2}$ for this model are 16.961 and 0.662 , respectively. For stream orders $>3$, the final model is a linear model that was best described by frequency and magnitude variables, which describe how often hydrological events occurs and the availability of water in the stream respectively. Considering the higher flows in stream orders greater than 3 it makes sense that the amount of water and frequency of floods and droughts will have major impacts on the biological communities found there. The variables selected for the

final model include one frequency variable that describes the variability in the high pulse count (FH2) and one magnitude variable that describes the specific mean annual minimum flow (ML22). Both variables had two generalized bell MFs. The RMSE and $R^{2}$ for this model are 15.300 and 0.720 respectively.

\subsection{Impacts of bioenergy managements}

In order to determine the individual impacts of each bioenergy management on the stream health of the watershed, thirteen scenarios were performed where a single management, such as continuous corn, was applied to all agricultural regions (agricultural, pasture, and marginal lands) within the watershed (43\% of the watershed). Figure 3 identifies all subbasins where bioenergy managements were applied.

Figure 3. 
Stream health scores were then calculated and compared to the current (base) condition. Figure 4 shows the stream segments that were degraded (dropped to a lower IBI class), did not change, and improved (increased to a higher IBI class) when continuous canola was applied to all agricultural regions in the watershed. Similar maps for each of the other twelve bioenergy managements are presented in Figure A2 in the Supplementary Materials.

Figure 4.

As can be seen in Figure 4, the majority of the streams showed no change in IBI class. This was the case for all thirteen bioenergy managements. These regions of no change mainly correspond to subbasins that have no bioenergy management applied to them (Figure 3). However the regions in which the management were applied both improvements and degradations can been seen. Table 2 summaries the overall improvements, no change, and degradations for each scenario. As can be seen in Table 2, in the case of continuous canola, at least $68 \%$ of the total stream length of the watershed showed no change. This shows that for the majority of the region the bioenergy managements have no impact. However, Scenario 12 (sorghum-soybean) had the greatest improvement in stream health when compared to the base condition. This is due to increased seasonal flows seen with this management, which improves the environmental conditions thus increasing the variable scores in the stream health models. Similar results were seen in Love and Nejadhashemi (2011) and Einheuser et al. (2013a). Meanwhile Scenarios 1 and 11 (continuous canola and native grass, respectively) had the greatest decrease in stream health when compared to the base condition. Continuous canola is an intensive management which can lead to negative impacts to the environment. Similar results for continuous canola were seen in Love and Nejadhashemi (2011) and Einheuser et al. (2013a). Native grass applications can lead to higher levels of evapotranspiration, which lowers the 
amount of water making it to river systems and thus lowering hydrological variable values and lowering the stream health scores based on them.

Table 2.

Another analysis preformed on each scenario was to determine the percentage of the total river that fell in to the categories of Satisfactory, Fair, and Unsatisfactory. For this analysis, streams with either Excellent or Good IBI classes were considered Satisfactory; streams with a Fair IBI class were considered Fair; and streams with either Poor or Very Poor IBI classes were considered as Unsatisfactory. Table 3 summarizes these percentages. As can be seen in Table 3 , Scenario 9 (corn stover-soybean) has the highest percentage of satisfactory streams (46\%) as well as the lowest percentage of unsatisfactory streams (15\%). This is due to the fact that corn stover provides winter and early spring cover that controls surface runoff improving the conditions within the stream. Scenario 8 (corn-soybean-rye) was similar to Scenario 9 by the fact that it also has the highest percentage of satisfactory streams but it also has the highest percentage of unsatisfactory streams (17\%). This was due to the balancing of the negative impacts of growing corn with the cover provided by the rye. During the corn cycle there would be increase surface runoff leading to lower stream health scores; while the rye cycle reduces surface runoff lowering the surface runoff and increasing the stream health scores. This shows that while Scenario 12 had the greatest improvement of all the scenarios, Scenario 9 has the healthiest stream system. It is also interesting to note that the largest percentage of unsatisfactory streams $(17 \%)$ is the same percentage of unsatisfactory streams in the base condition.

\section{Table 3.}


Table 4 compares the means of the hydrological variables before and after implementation of bioenergy crop rotation scenarios. As can be seen in Table 4, the hydrological variable means for the base condition are significantly higher than those for the scenarios in all cases. This indicates that the selected hydrological variables are not only sensitive to the implementation of the crop rotations, but also that there is a significant impact on the hydrological processes in the system when the crop rotations were introduced. However, unlike the single pattern seen when comparing the base condition to the scenarios, comparisons between the crop rotations show greater variability. For DL16 and ML22, no significant differences were seen between all the crop rotations (Table 4). This indicates that even though there was a noticeable difference between means of hydrological variable (base versus scenarios), there was no discernable difference between the scenarios despite the fact that the crop rotations have different intensities and operations. However, this is not the case for DL11 and FH2. For DL11, only S3 and S10 were significantly different from the rest of the scenarios as well as themselves (Table 4). This indicates that the continuous corn and miscanthus rotations altered the daily flow than all the other scenarios. For FH2, only S6, S8, and S10 were significantly different from the rest of the scenarios with slightly higher values (Table 4). This was expected since the continuous soybean, corn soybean rye, and miscanthus rotations required relatively more intensive management systems compared to other scenarios.

Table 4.

\subsection{Best bioenergy landscape}

After the development of the stream health models, the GA was used to create different bioenergy landscapes. This allowed for a guided progression toward a near optimal solution by optimizing the type and placement of bioenergy managements within the Flint River Watershed. 
After two thousand runs the best overall stream health score obtained was 50.93. This was higher than initial (base) condition, which had a score of 48.19. Figure 5 show the individual stream health scores for the base condition and the final bioenergy landscape respectively.

Figure 5.

As can been seen when comparing the scenarios, the majority of the stream segments fall within the same IBI class (70\% of all streams). This make it difficult to determine if the proposed bioenergy landscape had any impact on improving the stream health for the region. Therefore, a Wilcoxon Signed-Ranks statistical test was performed on the individual stream health scores to determine if there was a significant improvement when the bioenergy managements were applied to the region. The Wilcoxon Signed-Ranks test is a non-parametric technique that calculates the difference between two sets of observations by ranking the differences between paired values (Pratt, 1959). Due to the presence of ties and zeros in the differences between paired values, the method presented by Pratt (1959) was used to calculate the p-value for the individual stream health scores in both runs (base and final). The p-value of this analysis was less than 0.01, which indicates that there is a significant change between the base conditions and the final bioenergy landscape. Therefore it can be concluded that sustainable bioenergy crop expansions can be achieved through a carful design of the landscape, despite the fact that the area under agricultural practices was increased.

Figure A3 (Supplementary Materials) displays the locations of the bioenergy management applications within the study area for the final bioenergy landscape. And to better summaries this, Table 5 presents the percentages of each bioenergy management used based on the total agricultural area of the region. 


\section{Table 5.}

As can been seen in Table 5, the dominant bioenergy management was Scenario 10 (miscanthus), followed by Scenario 8 (corn-soybean-rye), Scenario 9 (corn stover-soybean), and Scenario 7 (corn-soybean). This does not match the conclusions drawn from the bioenergy scenario analysis, where Scenario 12 (sorghum-soybean) was predicted to have the greatest improvement to stream health scores. However, since the bioenergy scenario analysis was done one management at a time it was unable to take into account the improvements seen when bioenergy managements are combined. This shows how the placement of individual bioenergy managements has a significant impact on the resulting stream health scores.

\section{Conclusions}

In order to optimize the bioenergy landscape design, with respect to stream health, a series of models including SWAT, HIT, ANFIS, and GA were integrated for the Flint River Watershed. SWAT simulated daily stream flow data, which was used as inputs in the HIT model to calculate 171 biologically relevant stream flow indices. Bayesian variable selection was used to reduce the number of variables that were passed to ANFIS to develop the final stream health models. Once the stream health models were developed, they were used to estimate individual IBI scores for all stream segments and overall stream health scores for the entire watershed. The GA was used to guide the selection and placement of bioenergy managements within the watershed to achieve the highest overall stream health score.

To determine the impacts of individual bioenergy managements, thirteen scenarios were performed, where each scenario represents a different management applied to all agricultural lands within the watershed. It was found that the sorghum-soybean management (Scenario 12) 
showed the greatest stream health improvement, with a $19 \%$ increase in individual stream IBI classes (Table 2) with respect to the total river length for the region. However when percentages of IBI classes were analyzed, the corn stover-soybean management (Scenario 9) had both the highest percentage of Satisfactory (Excellent and Good IBI classes) streams at 46\% (Table 3) and the lowest percentage of Unsatisfactory (Poor and Very Poor IBI classes) streams at 15\% (Table 3). This indicates that when bioenergy managements are applied individually to the study area using only a sorghum-soybean management will yield the most improvement to stream health, while using only a corn stover-soybean management will yield the healthiest stream system.

The implementation of mixed bioenergy managements was performed to find a near optimum solution that maximized the stream health score for the region. After two thousand runs of the GA, the highest overall stream health achieved was 50.93. This was an improvement from the initial overall stream health of 48.19. And while the actual difference between these two scores is small (only 2.74), a Wilcoxon Signed-Ranks test on the individual stream health scores indicated that this was as a significant increase at the $1 \%$ significance level. The most commonly implemented bioenergy management for the final landscape was miscanthus $(27.07 \%)$, followed by corn-soybean-rye (19.00\%), corn stover-soybean $(18.09 \%)$, and corn-soybean $(16.43 \%)$. This did not match the analysis of the individual bioenergy management scenarios. However, those thirteen scenarios did not take into account the interactions between managements that could yield better stream conditions as was the case with the final bioenergy landscape.

The models developed in this study can be used by decision makers, allowing them to develop sustainable watershed level bioenergy landscapes that improve the overall stream health conditions. In order to improve the predictability and reliability of the stream health predictor 
models used in this study, future studies should include both water quantity and quality variables as well as utilize both fish and macroinvertebrate biological indicators. Furthermore, studies considering additional aspects of ecohydrology should be considered for a more holistic approach to sustainable environmental management.

\section{Acknowledgments}

This work is supported by the USDA National Institute of Food and Agriculture, Hatch project MICL02359.

\section{References}

Adriaenssens, V., Baets, B.D., Goethals, P.L., Pauw, N.D., 2004. Fuzzy rule-based models for decision support in ecosystem management. Sci. Total. Environ. 319(1), 1-12.

Arabi, M., Govindaraju, R.S., Hantush, M.M., 2006. Cost-effective allocation of watershed management practices using a genetic algorithm. Water Resour. Res. 42(10), W10429.

Brazner, J., Danz, N., Niemi, G., Regal, R., Trebitz, A., Howe, R., Hanowski, J., Johnson, L., Ciborowski, J., Johnston, C., Reavie, E., Brady, V., Sgro, G., 2007. Evaluation of geographic, geomorphic and human influences on Great Lakes wetland indicators: A multi-assemblage approach. Ecol. Indic. 7(3), 610-635.

Butcher, J.T., Stewart, P.M., Simon, T.P., 2003. A Benthic Community Index for streams in the Northern Lakes and Forests Ecoregion. Ecol. Indic. 3(3), 181-193.

Chen, Q., Mynett, A.E., 2003. Integration of data mining techniques and heuristic knowledge in fuzzy logic modelling of eutrophication in Taihu Lake. Ecol. Model. 162(1), 55-67. 
Egbendewe-Mondzozo, A., Swinton, S.M., Izaurralde, R.C., Manowitz, D.H., Zhang, X., 2013. Maintaining environmental quality while expanding biomass production: Sub-regional US policy simulations. Energy Policy 57, 518-531.

Einheuser, M.D., Nejadhashemi, A.P., Sowa, S.P., Wang, L., Hamaamin, Y.A., Woznicki, S.A., 2012. Modeling the effects of conservation practices on stream health. Sci. Total. Environ. 435-436, 380-391.

Einheuser, M.D., Nejadhashemi, A.P., Woznicki, S.A., 2013a. Simulating stream health sensitivity to landscape changes due to bioenergy crops expansion. Biomass Bioenergy 58, 198-209.

Einheuser, M.D., Nejadhashemi, A.P., Wang, L., Sowa, S.P. Woznicki, S.A., 2013b. Linking biological integrity and watershed models to assess the impacts of historical land use and climate changes on stream health. Environ. Manage. 51(6), 1147-1163.

EPA, 2014. Water: Healthy Watersheds. http://water.epa.gov/polwaste/nps/watershed/hydrologic.cfm/ (accessed 15.01.15).

Farrell, A.E., Plevin, R.J., Turner, B.T., Jones, A.D., O'hare, M., Kammen, D.M., 2006. Ethanol can contribute to energy and environmental goals. Science 311(5760), 506-508.

Gasparatos, A., Stromberg, P., Takeuchi, K., 2013. Sustainability impacts of first-generation biofuels. Anim. Front. 3(2), 12-26.

Gassman, P.W., Reyes, M.R., Green, C.H., Arnold, J.G., 2007. The soil and water assessment tool: historical development, applications, and future research directions. T. ASABE 50, $1211-1250$. 
Giri, S., Nejadhashemi, A.P., Woznicki, S.A., 2012. Evaluation of targeting methods for implementation of best management practices in the Saginaw River Watershed. J. Environ. Manage. 103, 24-40.

Goldemberg, J., 2007. Ethanol for a sustainable energy future. Science 315(5813), 808-810.

Green, P.J., 1995. Reversible jump Markov chain Monte Carlo computation and Bayesian model determination. Biometrika 82(4), 711-732.

Groom, M.J., Gray, E.M., Townsend, P.A., 2008. Biofuels and biodiversity: principles for creating better policies for biofuel production. Conserv. Biol. 22(3), 602-609.

Hamaamin, Y.A., 2014. Applications of soft computing and statistical methods in water resources management. Dissertation, Michigan State University.

Hamaamin, Y.A., Nejadhashemi, A.P., Einheuser, M.D., 2013. Application of fuzzy logic techniques in estimating the regional index flow for Michigan. T. ASABE 56(1), 103115.

Herman, M.R., Nejadhashemi, A.P., 2015. A review of macroinvertebrate-and fish-based stream health indices. Ecohydrol. Hydrobiol. 15(2), 53-67.

Jang, J.S.R., 1993. ANFIS: adaptive-network-based fuzzy inference system. IEEE Trans. Syst., Man, Cybern., Syst. 23(3), 665-685.

Karr, J.R., 1981. Assessment of Biotic Integrity Using Fish Communities. Fisheries 6(6), 21-27.

Karr, J.R., 1999. Defining and measuring river health. Freshwater Biol. 41(2), 221-234. 
Karr, J.R., Dudley, D.R., 1981. Ecological perspective on water quality goals. Environ. Manage. $5(1), 55-68$.

Kennard, M.J., Mackay, S.J., Pusey, B.J., Olden, J.D., Marsh, N., 2010. Quantifying uncertainty in estimation of hydrologic metrics for ecohydrological studies. River Res. Appl. 26(2), $137-156$.

Krause, J.R., Bertrand, K.N., Kafle, A., Troelstrup, Jr. N.H., 2013. A fish index of biotic integrity for South Dakota's Northern Glaciated Plains Ecoregion. Ecol. Indic. 34, 313322.

Landis, D.A., Gardiner, M.M., van der Werf, W., Swinton, S.M., 2008. Increasing corn for biofuel production reduces biocontrol services in agricultural landscapes. Proc. Natl. Acad. Sci. U.S.A. 105(51), 20552-20557.

Leigh, C., Stubbington, R., Sheldon, F., Boulton, A.J., 2013. Hyporheic invertebrates as bioindicators of ecological health in temporary rivers: A meta-analysis. Ecol. Indic. 32, $62-73$.

Love, B.J., Einheuser, M.D., Nejadhashemi, A.P., 2011. Effects on aquatic and human health due to large scale bioenergy crop expansion. Sci. Total. Environ. 409(17), 3215-3229.

Love, B.J., Nejadhashemi, A.P., 2011. Environmental impact analysis of biofuel crops expansion in the saginaw river watershed. J. Biobased Mater. Bioenergy 5, 1-25.

Lunn, D.J., Whittaker, J.C., Best, N., 2006. A Bayesian toolkit for genetic association studies. Genet. Epidemiol. 30, 461-464. 
Lyons, J., 1992. Using the index of biotic integrity (IBI) to measure environmental quality in warmwater streams of Wisconsin. U.S. Department of Agriculture, Forest Service, North Central Experiment Station, St. Paul, Minnesota, General Technical Report NC-149.

Mack, J.J., 2007. Developing a wetland IBI with statewide application after multiple testing iterations. Ecol. Indic. 7(4), 864-881.

Maddock, I., 1999. The importance of physical habitat assessment for evaluating river health. Freshwater Biol. 41(2), 373-391.

MathWorks, 2014. Fuzzy Logic Toolbox. http://www.mathworks.com/products/fuzzy-logic/ (accessed 15.01.15).

MathWorks, 2015. Genetic Algorithm. http://www.mathworks.com/discovery/geneticalgorithm.html (accessed 30.01.15).

Metternicht, G., 2001. Assessing temporal and spatial changes of salinity using fuzzy logic, remote sensing and GIS. Foundations of an expert system. Ecol. Model. 144(2), 163-179.

Moriasi, D.N., Arnold, J.G., Van Liew, M.W., Bingner, R.L., Harmel, R.D., Veith, T.L., 2007. Model evaluation guidelines for systematic quantification of accuracy in watershed simulations. T. ASABE 50(3), 885-900.

MSU Planning \& Zoning Center, 2012. Saginaw Bay Watershed and Area of Concern. http://www.pscinc.com/LinkClick.aspx?fileticket=Hi_PFZU-xOI\%3D\&tabid=65 (accessed 01.03.15).

NASS, 2012. CropScape-Cropland Data Layer. http://nassgeodata.gmu.edu/CropScape/ (accessed 15.01.15). 
Navarro-Llácer, C., Baeza, D., Heras, J., 2010. Assessment of regulated rivers with indices based on macroinvertebrates, fish and riparian forest in the southeast of Spain. Ecol. Indic. 10(5), 935-942.

NED, 2014. National Elevation Dataset. http://ned.usgs.gov/index.html (accessed 15.11.14).

Neitsch, S.L., Arnold, J.G., Kiniry, J.R., Williams, J.R., 2011. Soil and water assessment tool theoretical documentation, version 2009. Temple, Tex.: USDA-ARS Grassland, Soil and Water Research Laboratory; http://swat.tamu.edu/media/99192/swat2009-theory.pdf (accessed 15.01.15).

Nejadhashemi, A.P., Shirmohammadi, A., Sheridan, J.M., Montas, H.J., Mankin, K.R., 2009. Case study: evaluation of streamflow partitioning methods. J. Irrig. Drain. Eng. 135(6), 791-801.

NRCS, 2014. Wed Soil Survey. http://websoilsurvey.sc.egov.usda.gov/App/WebSoilSurvey.aspx (accessed 01.06.14).

Nyakatawa, E.Z., Mays, D.A., Tolbert, V.R., Green, T.H., Bingham, L., 2006. Runoff, sediment, nitrogen, and phosphorus losses from agricultural land converted to sweetgum and switchgrass bioenergy feedstock production in north Alabama. Biomass Bioenergy 30(7), 655-664.

Olden, J.D., Poff, N.L., 2003. Redundancy and the choice of hydrologic indices for characterizing streamflow regimes. River Res. Appl. 19(2), 101-121.

Ott, R.L., Longnecker, M., 2001. An introduction to statistical methods and data analysis, 5th Ed., Duxbury, Belmont, Calif. 
Pander, J., Geist, J., 2013. Ecological indicators for stream restoration success. Ecol. Indic. 30, 106-118.

Pelletier, M.C., Gold, A.J., Gonzalez, L., Oviatt, C., 2012. Application of multiple index development approaches to benthic invertebrate data from the Virginian Biogeographic Province, USA. Ecol. Indic. 23, 176-188.

Pratt,J.W., 1959. Remarks on zeros and ties in the Wilcoxon signed rank procedures. J. Am. Stat. Assoc. 54(287), 655-667.

Ragauskas, A.J., Williams, C.K., Davison, B.H., Britovsek, G., Cairney, J., Eckert, C.A., Frederick, W.J., Hallett, J.P., Leak, D.J., Liotta, C.L., Mielenz, J.R., Murphy, R., Templer, R., Tschaplinski, T., 2006. The path forward for biofuels and biomaterials. Science 311(5760), 484-489.

Richter, B.D., Baumgartner, J.V., Powell, J., Braun, D.P., 1996. A method for assessing hydrologic alteration within ecosystems. Conserv. Biol. 10, 1163-1174.

Searchinger, T., Heimlich, R., Houghton, R.A., Dong, F., Elobeid, A., Fabiosa, J., Tokgoz, S., Hayes, D., Yu, T.H., 2008. Use of US croplands for biofuels increases greenhouse gases through emissions from land-use change. Science 319(5867), 1238-1240.

Seelbach, P.W., Wiley, M.J., Kotanchik, J.C., Baker, M.E., 1997. State of Michigan Department of Natural Resources. A Landscape-based Ecological Classification System for River Valley Segments in Lower Michigan (MI VSEC Version 1.0): Fisheries Research Report 2036. 
Stewart, I.T., Cayan, D.R., Dettinger, M.D., 2005. Changes toward earlier streamflow timing across western North America. J. Clim. 18(8), 1136-1155.

Texas A\&M University System, 2013. SWAT: Soil \& Water Assessment Tool. swat.tamu.edu (accessed 15.01.15).

Thomas, M.A., Ahiablame, L.M., Engel, B.A., Chaubey, I., Mosier, N., 2014. Modeling Water Quality Impacts of Cellulosic Biofuel Production from Corn Silage. BioEnerg. Res. 7(2), 636-653.

Vannote, R.L., Minshall, G.W., Cummins, K.W., Sedell, J.R., Cushing, C.E., 1980. The river continuum concept. Can. J. Fish. and Aquat. Sci. 37(1), 130-137.

Walters, D., Roy, A., Leigh, D., 2009. Environmental indicators of macroinvertebrate and fish assemblage integrity in urbanizing watersheds. Ecol. Indic. 9(6), 1222-1233.

Woznicki, S.A., Nejadhashemi, A.P., Ross, D.M., Zhang, Z., Wang, L., Esfahanian, A.H., 2015. Ecohydrological model parameter selection for stream health evaluation. Sci. Total Environ. 511, 341-353.

Wu, Y., Liu, S., 2012. Impacts of biofuels production alternatives on water quantity and quality in the Iowa River Basin. Biomass Bioenergy 36, 182-191.

Zhu, D., Chang, J., 2008. Annual variations of biotic integrity in the upper Yangtze River using an adapted index of biotic integrity (IBI). Ecol. Indic. 8(5), 564-572. 


\section{Figure Captions}

Figure 1. Flint River Watershed

Figure 2. Flow diagram of the development and scenario phases.

Figure 3. Map of agricultural lands within the Flint River Watershed.

Figure 4. Changes in IBI Class when continuous canola was applied to all agricultural lands in the watershed.

Figure 5. Individual stream health scores for the base condition and final solution. 


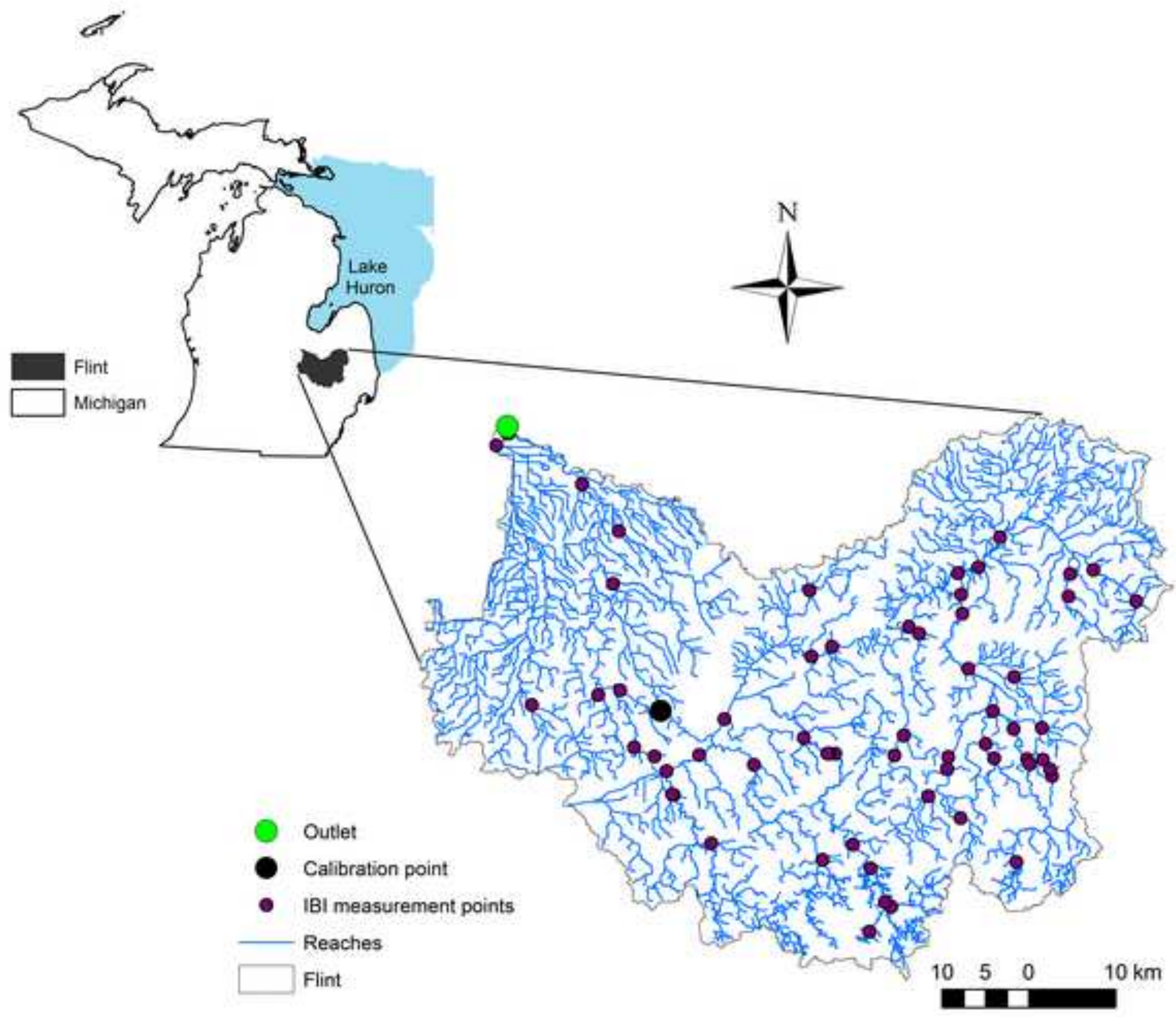



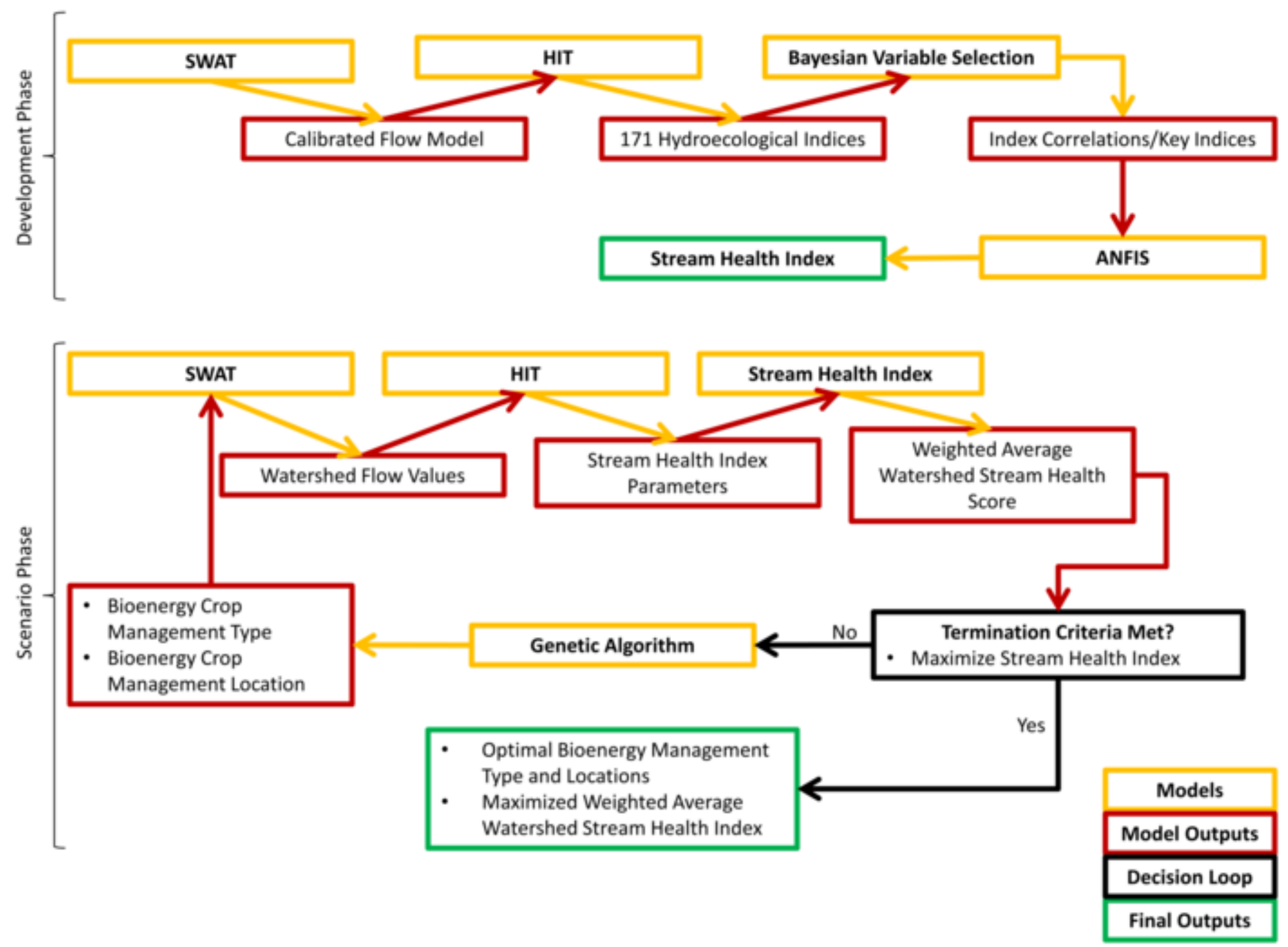


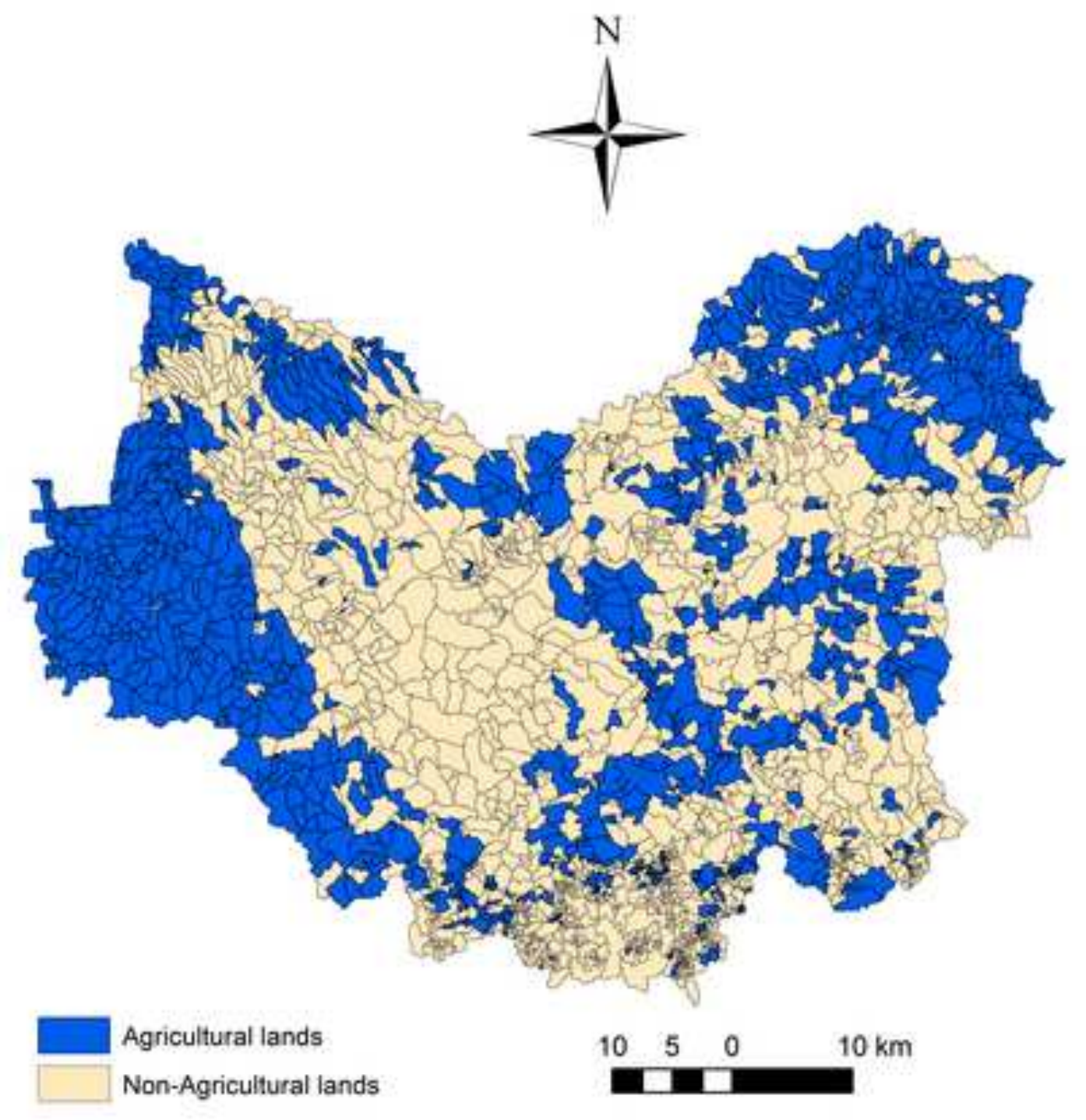

Figure 3

Non-Agricultural lands

$+$

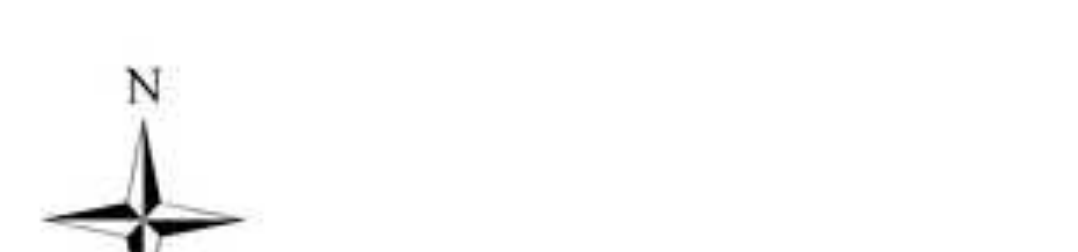


Figure 4
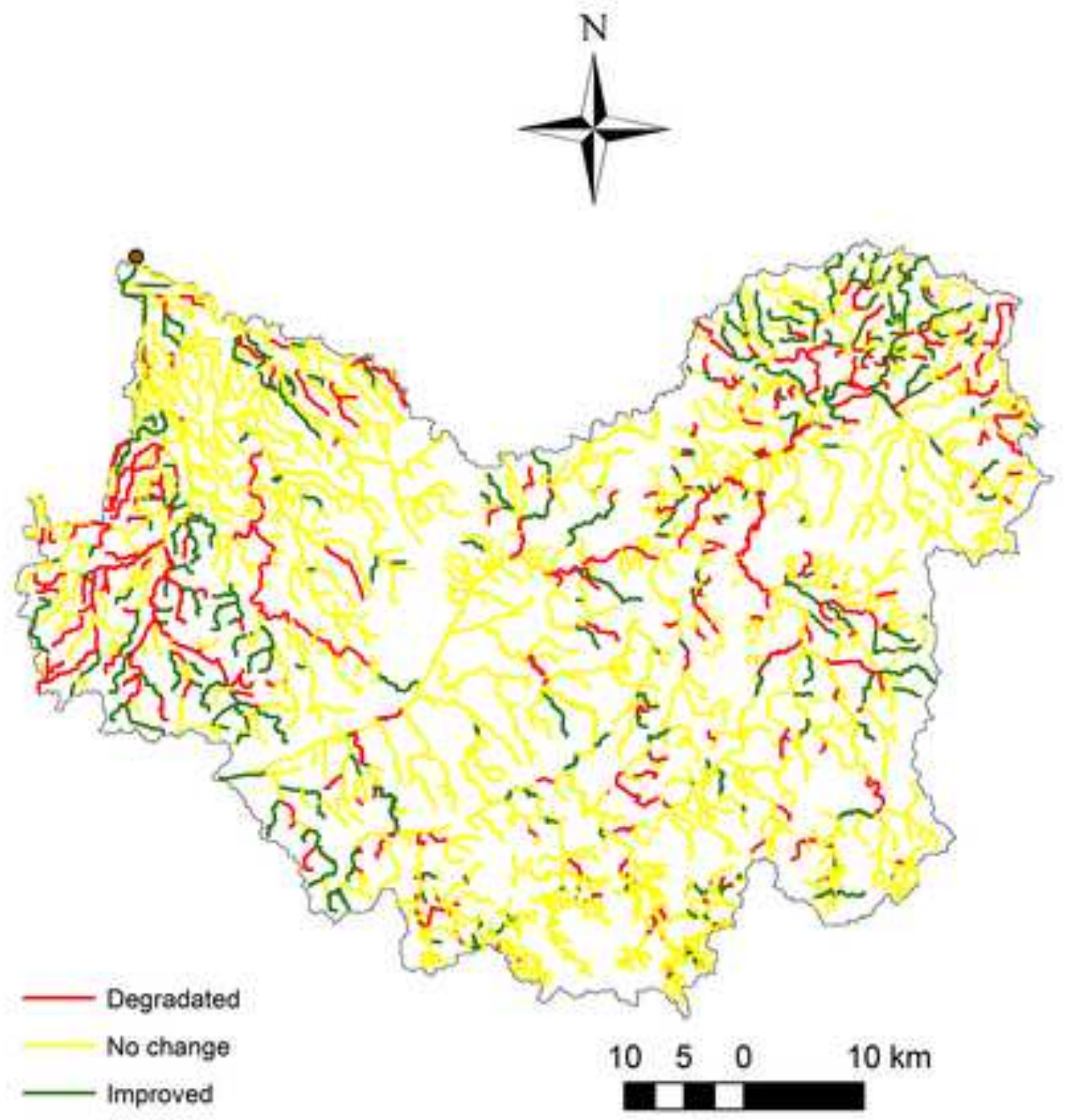
Base Condition

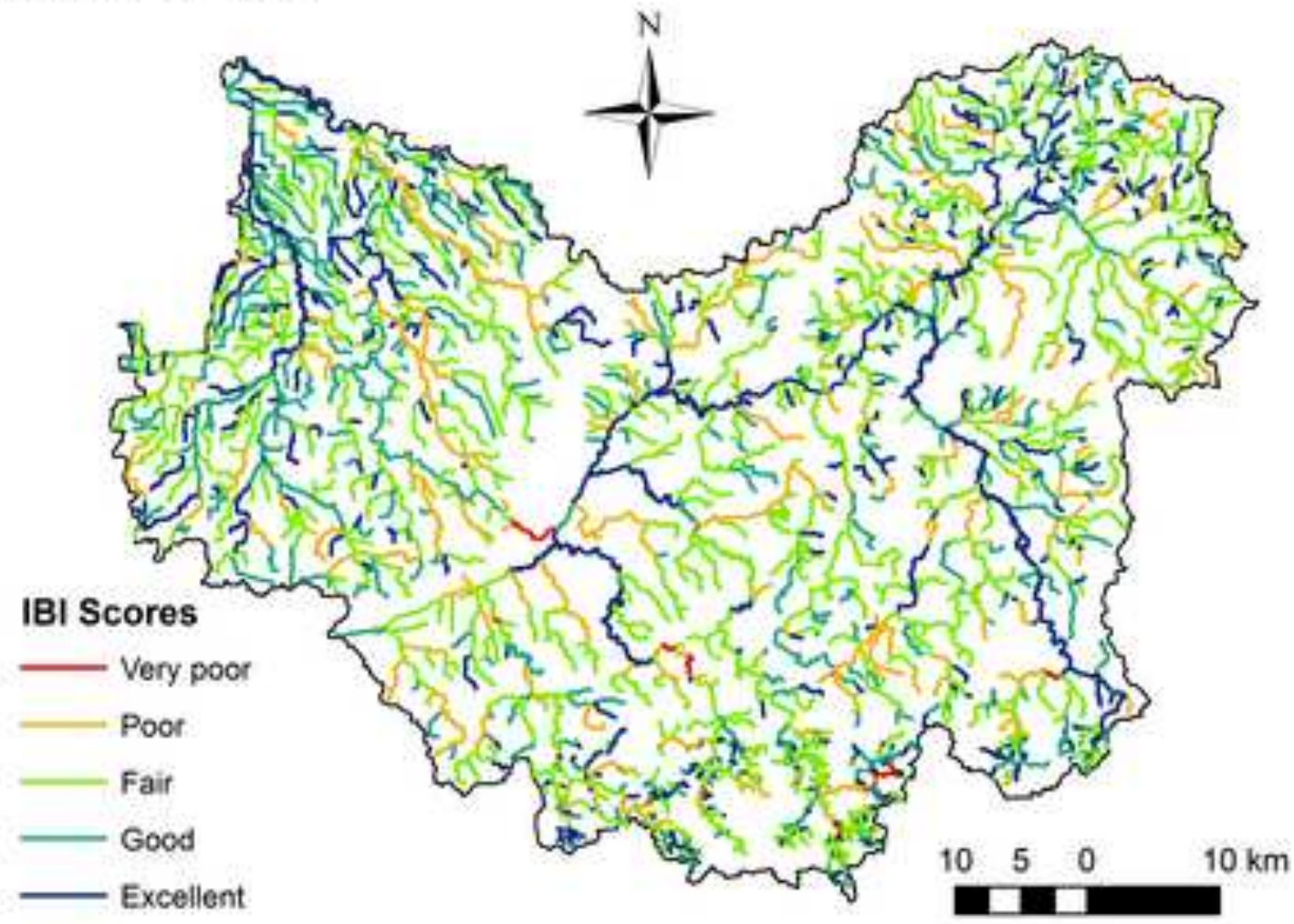

Final Solution

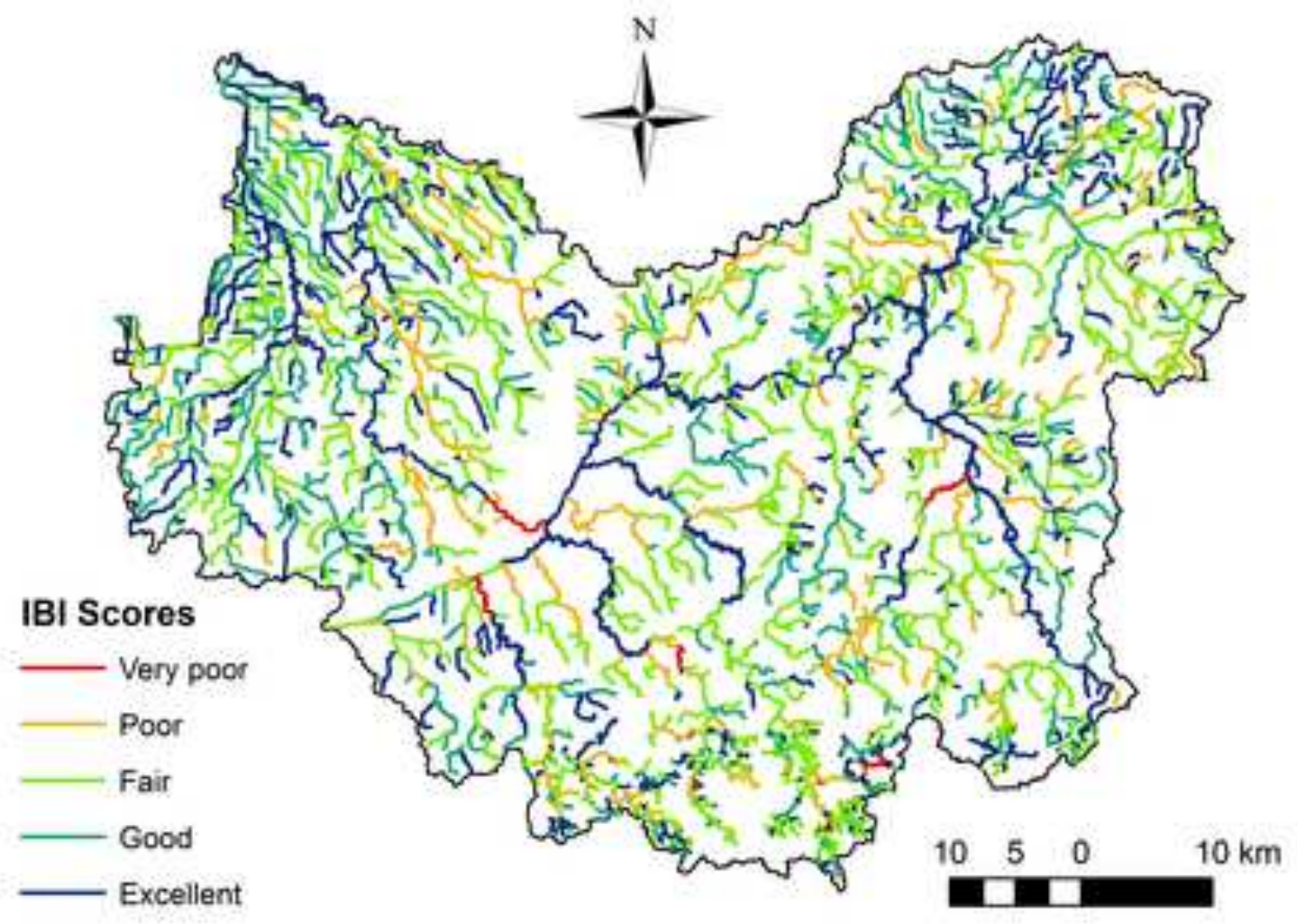


Table 1 . Ten year bioenergy crop rotations.

\begin{tabular}{|c|c|c|c|c|c|c|c|c|c|c|}
\hline \multirow{2}{*}{$\begin{array}{c}\text { Crop } \\
\text { Rotations* }\end{array}$} & \multicolumn{10}{|c|}{ Year } \\
\hline & 1 & 2 & 3 & 4 & 5 & 6 & 7 & 8 & 9 & 10 \\
\hline S1 & Canola & Rye & Canola & Canola & Rye & Canola & Canola & Rye & Canola & Canola \\
\hline $\mathrm{S} 2$ & Corn & Corn & Corn & Corn & Corn & Soybean & Corn & Corn & Corn & Corn \\
\hline $\mathrm{S} 3$ & Corn & Corn & Corn & Corn & Corn & Soybean & Corn & Corn & Corn & Corn \\
\hline & Stover & Stover & Stover & Stover & Stover & & Stover & Stover & Stover & Stover \\
\hline $\mathrm{S} 4$ & Soybean & Rye & Rye & Soybean & Rye & Rye & Soybean & Rye & Rye & Soybean \\
\hline S5 & Sorghum & Sorghum & Sorghum & Sorghum & Sorghum & Soybean & Sorghum & Sorghum & Sorghum & Sorghum \\
\hline S6 & Soybean & Soybean & Corn & Soybean & Soybean & Corn & Soybean & Soybean & Corn & Soybean \\
\hline S7 & Corn & Soybean & Corn & Soybean & Corn & Soybean & Corn & Soybean & Corn & Soybean \\
\hline S8 & Corn & Soybean & Rye & Corn & Soybean & Rye & Corn & Soybean & Rye & Corn \\
\hline S9 & $\begin{array}{l}\text { Corn } \\
\text { Stover }\end{array}$ & Soybean & $\begin{array}{l}\text { Corn } \\
\text { Stover }\end{array}$ & Soybean & $\begin{array}{l}\text { Corn } \\
\text { Stover }\end{array}$ & Soybean & $\begin{array}{l}\text { Corn } \\
\text { Stover }\end{array}$ & Soybean & $\begin{array}{l}\text { Corn } \\
\text { Stover }\end{array}$ & Soybean \\
\hline S10 & Miscanthus & Miscanthus & Miscanthus & Miscanthus & Miscanthus & Miscanthus & Miscanthus & Miscanthus & Miscanthus & Miscanthus \\
\hline S11 & $\begin{array}{l}\text { Native } \\
\text { Grass }\end{array}$ & $\begin{array}{l}\text { Native } \\
\text { Grass }\end{array}$ & $\begin{array}{l}\text { Native } \\
\text { Grass }\end{array}$ & $\begin{array}{l}\text { Native } \\
\text { Grass }\end{array}$ & $\begin{array}{l}\text { Native } \\
\text { Grass }\end{array}$ & $\begin{array}{l}\text { Native } \\
\text { Grass }\end{array}$ & $\begin{array}{l}\text { Native } \\
\text { Grass }\end{array}$ & $\begin{array}{c}\text { Native } \\
\text { Grass }\end{array}$ & $\begin{array}{l}\text { Native } \\
\text { Grass }\end{array}$ & $\begin{array}{l}\text { Native } \\
\text { Grass }\end{array}$ \\
\hline S12 & Sorghum & Soybean & Sorghum & Soybean & Sorghum & Soybean & Sorghum & Soybean & Sorghum & Soybean \\
\hline S13 & Switchgrass & Soybean & Switchgrass & Switchgrass & Switchgrass & Switchgrass & Switchgrass & Switchgrass & Switchgrass & Switchgrass \\
\hline
\end{tabular}

* Continuous Canola (S1), Continuous Corn (S2), Continuous Corn Stover (S3), Continuous Rye (S4), Continuous Sorghum (S5), Continuous Soybean (S6), Corn Soybean (S7), Corn Soybean Rye (S8), Corn Stover Soybean (S9), Miscanthus (S10), Native Grass (S11), Sorghum Soybean (S12), Switchgrass (S13). 
Table 2. Summary of the changes in IBI class for each scenario based on percent of total river length. Numbers that are bolded indicate the largest value while numbers that are italicized indicate the smallest values for each percent change.

\begin{tabular}{|c|c|c|c|c|c|c|c|c|c|c|c|c|c|}
\hline \multirow{2}{*}{$\begin{array}{l}\text { Percent } \\
\text { Change }\end{array}$} & \multicolumn{13}{|c|}{$\begin{array}{c}\text { Scenarios* } \\
(\%)\end{array}$} \\
\hline & S1 & S2 & S3 & S4 & S5 & S6 & S7 & S8 & S9 & S10 & S11 & S12 & S13 \\
\hline Increase & 16 & 15 & 18 & 16 & 17 & 11 & 16 & 18 & 18 & 15 & 15 & 19 & 15 \\
\hline No Change & 68 & 73 & 69 & 69 & 71 & 78 & 73 & 69 & 71 & 70 & 69 & 70 & 74 \\
\hline Decrease & 16 & 12 & 13 & 15 & 12 & 11 & 10 & 13 & 12 & 15 & 16 & 11 & 11 \\
\hline
\end{tabular}

* Continuous Canola (S1), Continuous Corn (S2), Continuous Corn Stover (S3), Continuous Rye (S4), Continuous Sorghum (S5), Continuous Soybean (S6), Corn-Soybean (S7), Corn-Soybean-Rye (S8), Corn Stover-Soybean (S9), Miscanthus (S10), Native Grass (S11), Sorghum-Soybean (S12), Switchgrass (S13). 
Table 3. Summary of the overall condition of the streams for each scenario based on percent of total river length. Numbers that are bolded indicate the largest value while numbers that are italicized indicate the smallest values for each overall condition.

\begin{tabular}{|c|c|c|c|c|c|c|c|c|c|c|c|c|c|c|c|}
\hline \multirow[t]{2}{*}{ IBI Class } & \multirow{2}{*}{$\begin{array}{c}\text { Overall } \\
\text { Condition }\end{array}$} & \multicolumn{14}{|c|}{$\begin{array}{c}\text { Scenarios* } \\
(\%)\end{array}$} \\
\hline & & Base & S1 & $\mathbf{S 2}$ & $\mathbf{S 3}$ & S4 & S5 & S6 & S7 & 58 & S9 & S10 & S11 & S12 & S13 \\
\hline $\begin{array}{c}\text { Excellent } \\
\text { Good }\end{array}$ & Satisfactory & 40 & 38 & 41 & 44 & 41 & 42 & 40 & 43 & 46 & 46 & 40 & 41 & 45 & 42 \\
\hline Fair & Fair & 43 & 46 & 44 & 40 & 42 & 42 & 43 & 42 & 37 & 39 & 43 & 42 & 39 & 42 \\
\hline $\begin{array}{c}\text { Poor } \\
\text { Very Poor }\end{array}$ & Unsatisfactory & 17 & 16 & 15 & 16 & 17 & 16 & 17 & 15 & 17 & 15 & 17 & 17 & 16 & 16 \\
\hline
\end{tabular}

* Continuous Canola (S1), Continuous Corn (S2), Continuous Corn Stover (S3), Continuous Rye (S4), Continuous Sorghum (S5), Continuous Soybean (S6), Corn-Soybean (S7), Corn-Soybean-Rye (S8), Corn Stover-Soybean (S9), Miscanthus (S10), Native Grass (S11), Sorghum-Soybean (S12), Switchgrass (S13) 
Table 4. Statistical analysis of the base condition and bioenergy crop rotations with respect the hydrological variables.

\begin{tabular}{|c|c|c|c|c|c|c|c|c|c|c|c|c|c|c|}
\hline \multirow{2}{*}{$\begin{array}{l}\text { Hydrological } \\
\text { Variables } * *\end{array}$} & \multirow{2}{*}{$\begin{array}{c}\text { Base } \\
\text { Condition } \\
\end{array}$} & \multicolumn{13}{|c|}{ Crop Rotations* } \\
\hline & & S1 & $\mathrm{S} 2$ & S3 & $\mathrm{S} 4$ & S5 & S6 & S7 & S8 & S9 & $\mathrm{S} 10$ & $\mathrm{~S} 11$ & $\mathrm{~S} 12$ & $\mathrm{~S} 13$ \\
\hline DL16 & $11.19^{\mathrm{a}}$ & $7.90^{b}$ & $8.00^{b}$ & $8.01^{b}$ & $8.00^{b}$ & $7.96^{\mathrm{b}}$ & $8.02^{b}$ & $7.98^{b}$ & $7.97^{b}$ & $7.98^{b}$ & $8.03^{b}$ & $7.89^{b}$ & $7.99^{b}$ & $8.05^{b}$ \\
\hline DL11 & $0.22^{\mathrm{a}}$ & $0.15^{\mathrm{bd}}$ & $0.15^{\mathrm{bcd}}$ & $0.15^{\mathrm{c}}$ & $0.15^{\mathrm{bcd}}$ & $0.15^{\mathrm{bcd}}$ & $0.15^{\text {bd }}$ & $0.15^{\text {bd }}$ & $0.15^{\mathrm{bcd}}$ & $0.15^{\mathrm{cd}}$ & $0.14^{\mathrm{b}}$ & $0.14^{\text {bd }}$ & $0.15^{\mathrm{bcd}}$ & $0.15^{\mathrm{cd}}$ \\
\hline $\mathrm{FH} 2$ & $38.62^{\mathrm{a}}$ & $30.71^{\mathrm{b}}$ & $31.09^{\mathrm{bc}}$ & $31.10^{\mathrm{bc}}$ & $31.18^{\mathrm{bc}}$ & $31.03^{\mathrm{bc}}$ & $31.52^{\mathrm{c}}$ & $31.08^{\mathrm{bc}}$ & $31.56^{\mathrm{c}}$ & $30.99^{\mathrm{bc}}$ & $31.60^{\mathrm{c}}$ & $30.93^{b c}$ & $31.10^{\mathrm{bc}}$ & $31.35^{\mathrm{bc}}$ \\
\hline ML22 & $0.04^{\mathrm{a}}$ & $0.02^{\mathrm{b}}$ & $0.02^{\mathrm{b}}$ & $0.02^{\mathrm{b}}$ & $0.02^{\mathrm{b}}$ & $0.02^{\mathrm{b}}$ & $0.02^{\mathrm{b}}$ & $0.02^{\mathrm{b}}$ & $0.02^{\mathrm{b}}$ & $0.02^{\mathrm{b}}$ & $0.02^{\mathrm{b}}$ & $0.02^{\mathrm{b}}$ & $0.02^{\mathrm{b}}$ & $0.02^{\mathrm{b}}$ \\
\hline
\end{tabular}

* Continuous Canola (S1), Continuous Corn (S2), Continuous Corn Stover (S3), Continuous Rye (S4), Continuous Sorghum (S5), Continuous Soybean (S6), Corn Soybean (S7), Corn Soybean Rye (S8), Corn Stover Soybean (S9), Miscanthus (S10), Native Grass (S11), Sorghum Soybean (S12), Switchgrass (S13).

** Low Flow Pulse Duration in number of days (DL16), Annual Minimum Daily Flow Divided by the Median for the Entire Record - unit less (DL11), Variability in the High Pulse Count in year (FH2), Specific Mean Annual Minimum Flow in $\mathrm{m} 3 / \mathrm{s} / \mathrm{km} 2$ (ML22). 
Table 5. Final bioenergy landscape bioenergy management distribution based on percent of total area of implementation lands.

\begin{tabular}{cc}
\hline Bioenergy Management & $\begin{array}{c}\text { Percent Applicable } \\
\text { Land }\end{array}$ \\
\hline S1 & 0.40 \\
S2 & 0.53 \\
S3 & 1.75 \\
S4 & 3.01 \\
S5 & 4.86 \\
S6 & 4.38 \\
S7 & 16.43 \\
S8 & 19.00 \\
S9 & 18.09 \\
S10 & 27.07 \\
S11 & 2.73 \\
S12 & 1.29 \\
S13 & 0.46 \\
\hline
\end{tabular}

